\title{
AS RECEPÇões e AS CONFORMAÇões de PASSAdo e PRESENTE
}

\author{
Anderson Zalewski Vargas ${ }^{1}$
}

Recepção ${ }^{2}$ é um termo que tem se multiplicado nos últimos tempos no campo dos estudos históricos em geral e dos estudos antigos em particular. Ele pode ser facilmente encontrado em títulos de livros, artigos, de apresentações em eventos acadêmicos e mesmo de dissertações e teses. A edição deste dossiê é um sinal disto. Falta, contudo, muito a ser feito para considerar o termo como designador de um campo de estudos particular. Talvez seja quimérico esperar a constituição de um universo uniforme de estudos. No caso da história, uma das razões é a problemática relação entre o trabalho historiográfico e sua teorização. A existência de setores de teoria e metodologia nos departamentos de história universitários, praticamente autônomos, é um indicativo da relação inecessária entre a reflexão teórica sistemática e a prática dos historiadores. Pode ser relevante, mas não é essencial. ${ }^{3}$

Apesar disso, certa reflexão é sempre desejada, mesmo que ela não ofereça ferramentas e caminhos. Como observou Norma Cortês, em uma recepção particular do termo antigo, grego, theoria:

Teoria não visa estabelecimento de métodos científicos (modelos procedimentais que regulam e orientam as práticas da pesquisa histórica), e, no limite, encerra uma matriz contemplativa que obteve a excelência de seu melhor acabamento no mundo de Sofia. (...) Sendo breve, eu diria que serve apenas para fazer pensar embora isso não a notabilize, já que todas as áreas disciplinares também devem

\footnotetext{
${ }^{1}$ Professor do Departamento e Programa de Pós-graduação em História da UFRGS.

2 Salvo observação em contrário, são meus os destaques deste texto.

${ }^{3}$ Por vezes, este descolamento pode ser apresentado como indício de juízo negativo do contexto historiográfico. É como considero o conhecido lamento de Carlos Ginzburg elaborado em meados dos anos 90 e publicado no início dos anos 2000: "As teses céticas baseadas na redução da historiografia à sua dimensão narrativa ou retórica circulam já há alguns decênios, ainda que suas raízes sejam, como se verá, mais antigas. Como de costumes, os teóricos da historiografia que as propõem pouco se preocupam com o trabalho concreto dos historiadores. Mas este, também, depois de fazerem uma homenagem convencional à tendência linguística ou retórica em voga [destaque original], se mostram bem pouco inclinados a refletir sobre as implicações teóricas de sua profissão. Raramente a distância entre reflexão metodológica e prática historiográfica efetiva foi tão grande quanto nos últimos decênios." (2002, p.13-14).
}

Heródoto, Unifesp, Guarulhos, v. 4, n. 2, 2019.2 p. 07-17

DOI: $10.34024 /$ herodoto.2019.v4.10959 
fazer isso! Afinal, Teoria da História nos chama à contemplação e a uma atenta observação de nós mesmos. [itálico original] (2009, p. 14)

Da minha parte, acredito que a precisão de conceitos, o uso explícito de certas concepções e a própria reflexão teórica podem ter implicações práticas outras, desde que não seja apenas ilustrativa ou um argumento de autoridade $^{4}$. Também não se trata de um aprendizado interior, silencioso, incapaz de ser transmitido a terceiros. ${ }^{5}$ Fazendo parte da invenção do trabalho do historiador, constituindo-o, pode criar novos objetos de estudo pela simples nomeação diversa de uma documentação; ao estabelecer princípios, a reflexão teórica pode nos levar a fazer questões que de outra forma não faríamos e, assim, obter outras respostas.

Estética da Recepção data dos anos 60 do século XX, mas a História da Recepção nasceu, creio, no final dos 90 com a obra de Charles Martindale (Redeeming the text-1993). Nas palavras do próprio autor, é uma "versão historicizante" daquela estética inaugurada Hans Robert Jauss ${ }^{6}$ ainda nos anos 60. Alegadamente, teria sido conjugada com a Descontrução de Jacques Derrida, a Nova Crítica (New Criticism) e as teorias do diálogo de Mikhail Bakhtin e a hermenêutica de Hans-Georg Gadamer (1993, p. XIII, 01).

4 É o que Norma Cortês parece referir na seção que retirei da citação anterior: "Ela [a teoria], portanto, nem transmite fórmulas metódicas generalistas, nem possui qualquer primazia ou antecedência frente as demais áreas e especializações disciplinares. Teoria da História não serve para ensinar a fazer projetos de pesquisa, não sanciona a validade dos procedimentos metódicos adotados pelas demais áreas de interesse histórico e tampouco assegura a objetividade às escolhas intelectuais dos historiadores" (2009, p.14).

${ }_{5}^{5}$ Mesmo não desconsiderando completamente aspectos mais pessoais do sentido e impacto das reflexões teóricas, quero dizer que não se trata de uma questão de caráter religioso, como é implicado por Karen Armstrong em sua avaliação das distinções dos cristianismos oriental e ocidental: "A distinção entre fé esotérica e exotérica será extremamente importante na história de Deus. Não se limitaria aos cristãos gregos, mas judeus e muçulmanos também desenvolveriam uma tradição esotérica. A ideia de uma doutrina 'secreta' não era deixar as pessoas de fora. Basilio não falava de uma forma anterior de maçonaria. Simplesmente chamava a atenção para o fato de que nem toda verdade religiosa era capaz de ser expressa e definida de maneira clara e lógica. Algumas intuições religiosas tinham uma ressonância interior que só podia ser apreendida por cada indivíduo em seu próprio tempo, no que Platão chamou de theoria, 'contemplação'(...)" (1994, p. 122, 123, 126 e 127)

${ }^{6}$ Em 1979, Luiz Costa Lima publicou uma coletânea de textos da Estética da Recepção. Ela foi reeditada em 2002, em um contexto em que historiadores (como eu) puderam ler interessados em saber sua contribuição para análise interna de textos. Os prefácios às duas edições são úteis em diversos sentidos, inclusive para saber dos demais nomes daquela escola, de suas proposições e divergências. Lá estão textos de Wolfgang Iser, Kahrlheinz Stierle, Harald Weinrich e o muito conhecido dos brasileiros, Hans Ulrich Gumbrecht.

Heródoto, Unifesp, Guarulhos, v. 4, n. 2, 2019.2 p. 07-17

DOI: $10.34024 /$ herodoto.2019.v4.10959 
Como em outras situações, os profissionais da área histórica se defrontam com a tarefa de apropriação de teoria imaginada para outro universo, no caso a Literatura. O empreendimento não é simples e não me parece concluído - aliás, uma das teses de Redeeming the text é afirmar que há virtudes em reconhecer o caráter provisório dos nossos procedimentos analíticos (1993, p. XIV).

Há, no entanto, outras vertentes das histórias da recepção, de forma que a gênese também pode ser localizada no início deste século, como o fez Anastasia Bakogianni (2016, p. 5) ao considerar seminal o texto de Lorna Hardwick (2003). Encontramos consideráveis diferenças e variações. A despeito da referência à Escola de Constance, Hardwick, particularmente preocupada com apropriações do Classicismo, afirma a diversidade de teoria e métodos de investigação para tratar de uma variedade considerável de objetos, temas e âmbitos de recepção. ${ }^{7}$ Esta variedade pode ser constatada, como o fez James Tatum (2014, p. 90), pela leitura apresentação da revista Classics Reception Journal, criada em 2009 para oferecer canal específico para a um campo de estudos ainda em consolidação:

Classical Receptions Journal abarca todos os aspectos da recepção dos textos e da cultura material da Grécia e Roma antigas, desde a antiguidade até os dias atuais. O objetivo é explorar as relações entre transmissão, interpretação, tradução, transferência, reescrita, reelaboração e repensar do material grego e romano em outros contextos e culturas. Aborda as implicações tanto para os contextos receptores quanto para os antigos, e compara diferentes tipos de interações linguísticas, textuais e ideológicas.

A revista promove intercâmbios e debates interdisciplinares na interface entre os assuntos. Por isso, recebe propostas de pesquisadores em Arqueologia, Arquitetura, História da Arte, Literatura Comparada, Cinema, História Intelectual, História da Erudição, Ciência Política, Estudos Teatrais e Estudos de Tradução, assim como dos Clássicos e da História Antiga. ${ }^{8}$

\footnotetext{
7 Ao invés de uma teoria ou um método, apresenta key assumptions (2003, p. 16-17).

8 "Classical Receptions Journal covers all aspects of the reception of the texts and material culture of ancient Greece and Rome from antiquity to the present day. It aims to explore the relationships between transmission, interpretation, translation, transplantation, rewriting, redesigning and rethinking of Greek and Roman material in other contexts and cultures. It addresses the implications both for the receiving contexts and for the ancient, and compares different types of linguistic, textual and ideological interactions. The journal promotes cross-disciplinary exchange and debates at the interface between subjects. It therefore welcomes submissions from researchers in Archaeology, Architecture, Art History, Comparative Literature, Film, Intellectual History, History of
}

Heródoto, Unifesp, Guarulhos, v. 4, n. 2, 2019.2 p. 07-17

DOI: 10.34024 /herodoto.2019.v4.10959 
Não podemos, portanto, esperar dos textos deste dossiê uniformidade temática e de tratamento. Podemos, por outro lado, lê-los de forma a pensarmos o que revelam de alternativo em relação a estudos de gênero semelhante (os "Usos da História", por exemplo), contribuindo para a constituição de uma subárea de estudos históricos, a da Recepção da Antiguidade

A despeito da estonteante variedade indicada por Tatum e confirmada pelos artigos que seguem, existem algumas assunções que devem, na minha opinião, ser destacadas. Em primeiro lugar, recepção significa apropriação ativa, o que ressalva a centralidade do leitor ou intérprete. Isto é, o reconhecimento de que os sentidos de uma obra, não estão determinados definitivamente no momento de sua elaboração, não existem em si. É princípio central à Estética da Recepção, acatado por Martindale e Hardwick, e que me parece expresso por Alberto Manguel ao tratar da leitura:

É, contudo, em cada caso é o leitor que lê o sentido; é o leitor que confere a um objeto, lugar ou acontecimento uma certa legibilidade possível, ou que a reconhece neles: é o leitor que deve atribuir significado a um sistema de signos e depois decifrá-lo. (1997, p. 19)

É preciso considerar, claro, a existência de pelo menos um outro polo em todo ato de recepção: a obra, seja uma matéria de jornal, um romance, um filme, uma escultura.... Estes dois polos existem de forma independente, podendo a apropriação ser pensada em termos de correspondência ou adequação, ou a recepção consiste na interação entre ambos? Tendo se constituído contra a ideia de que uma obra simplesmente reflete o seu tempo (sociedade, economia, classe...) ou possui uma verdade imanente, a Estética da Recepção, e muitas das histórias delas derivadas, pretendeu que o sentido é constituído pela interação entre os polos envolvidos ${ }^{9}$. Neste diálogo, a imaginação do observador organiza, filtra e seleciona, ela cria (LIMA, 2002, p. 16).

Há diversas implicações importantes disto. Não há uma "tradição" existente por si mesma, a influenciar ou a moldar a posteridade. Inexiste, pois, "legado", a não ser que este seja um conjunto heteróclito de

Scholarship, Political Science, Theatre Studies and Translation Studies as well as from those in Classics and Ancient History." Disponível em: https://academic.oup.com/crj/pages/About. Acesso em 25 fev. 2020.

${ }^{9}$ Segundo Luiz Costa Lima, Jauss, pelo menos inicialmente, manteve a separação entre objeto e observador, não tendo aprendido a "lição gadameriana" (2002, p. 18-19).

Heródoto, Unifesp, Guarulhos, v. 4, n. 2, 2019.2 p. 07-17

DOI: $10.34024 /$ herodoto.2019.v4.10959 
interpretações sempre sujeitas a alterações, podendo ser mesmo rupturas, como quando a atenção majoritária se volta de um assunto para outro ou revoluciona o entendimento de aspecto particular do passado. A eliminação da ideia de um referente sólido para interpretar os vestígios da história confere novo sentido e relevância ao juízo das suas diferentes apropriações, porque sempre avaliamos, mesmo que em graus e de formas diferentes, o que é dito do passado e feito a partir de suas recepções. Por outro lado, perdemos os antolhos que nos impedem de explorar apropriações à primeira vista inaceitáveis por parecerem equivocadas ou ridículas. Porque não estamos interessados na verdade de uma recepção, mas nela mesma. E podemos ainda nos perguntar sobre como ela reformulou a visão do passado, instaurando uma nova realidade.

Deixando de lado nossa concordância ou discordância, podemos nos dedicar a entender e explorar os sentidos de curiosas visões sobre o Egito Antigo, como as da Egiptomania, responsável pela pirâmide do Louvre e pela série de filmes Múmia. É o que nos oferece o artigo dos colegas portugueses José das Candeia Sales e Susana Mota, o primeiro professor da Universidade Aberta de Lisboa e a segunda pesquisadora Centro de Humanidades (CHAM) da Universidade Nova de Lisboa, integrante do grupo de pesquisa A Antiguidade e a sua Recepção. O principal objetivo dos colegas é avaliar o conjunto de noções e termos do universo da recepção do Egito Antigo. Tutankhamon em Portugal. Relatos da imprensa portuguesa (1922-1939) é realmente um Contributo para os Estudos de Recepção do Antigo Egipto por fazer uma admirável discussão conceitual e apresentar conclusão que deve surpreender a muitos, como surpreendeu a mim. $\mathrm{O}$ texto expõe seu corpus de pesquisa e apresenta os jornais portugueses do início do século XX como artífices da recepção do Egito Antigo. Outro aspecto a ser destacado: trata-se de um estudo de apropriação da Antiguidade Oriental, o que não é objeto da atenção geral dos especialistas da área.

O artigo individual de Susana Mota versa igualmente sobre o Oriente Antigo e apresenta análoga preocupação teórico-metodológica. $\mathrm{O}$ seu título, como os demais deste dossiê, é indicativo da diversidade de objetos de estudo propiciadas pelos estudos de recepção. A recepção da Antiga Mesopotâmia no cinema tem como objeto as películas do cinema mudo, largamente desconhecidas (por mim e, suponho, pela maioria dos leitores deste dossiê). Seu subtítulo, ademais, indica a sua complexidade: Uma viagem pelo universo da escrita em movimento e seus antepassados artísticoliterários. Além de considerar uma noção corrente de contexto, a autora busca outras narrativas escritas e imagéticas em que se inserem as

Heródoto, Unifesp, Guarulhos, v. 4, n. 2, 2019.2 p. 07-17

DOI: $10.34024 /$ herodoto.2019.v4.10959 
apropriações cinematográficas da Antiga Mesopotâmia. A começar pelo texto bíblico, seguindo por fontes antigas e alcançando a as recepções filosóficas da modernidade. Neste percurso, Susana Mota revela de forma evidente o que pode ser constatado na maioria dos artigos deste dossiê: é importante ser um especialista em História Antiga para bem realizar um estudo de apropriação da Antiguidade. É atributo relevante para identificar as invocações daquele passado - que podem passar desapercebidas aos demais especialistas - e também para selecionar fontes antigas e ter condições de aproveitar a bibliografia pertinente sobre o tema estudado. Essas qualificações aumentam as possibilidades de explorar, de forma satisfatória, as potencialidades de análise, as quais nunca serão esgotadas considerando a infinidade de caminhos possíveis.

Camilla Ferreira Paulino da Silva é doutora em História da Roma Antiga pela Universidade Federal do Espírito Santo e esta formação é de fundamental importância em seu artigo Análise do éthos de Otávio na série Rome (HBO). Porque seu objetivo é mostrar que a imagem de Otávio transmitida pela conhecida minisérie é devedora de uma antiga "tradição literária", o que implica conhecer os textos latinos constituidores de certa representação daquela personagem. O termo éthos indica um caminho analítico retórico, sendo que Camila da Silva corretamente concilia a noção aristotélica - relativa a discursos orais - com a de Dominique Maingueneau - éthos discursivo - para proceder à avaliação da série. O leitor atento observará a contradição existente entre minha crítica à ideia de "tradição" e o uso da mesma neste artigo. O mesmo leitor deverá lembrar igualmente o que escrevi sobre o campo da História da Recepção: ele é consideravelmente desuniforme em razão da amplitude de suas investigações e da variedade de suas concepções constituintes.

Jorge Elices Ocón, pós-doutorando na UNIFESP com pesquisa sobre "recepção das estátuas antigas no mundo islâmico e al-Andalus e as conexões atuais com as destruições de antiguidades na Síria e Iraque pelo DAESH"10, é o autor de Memorias de África: La superioridad de los Negros sobre los Blancos (Kitāb Fakhr al-Sūdān 'alā al-Bìdàn). No texto deste dossiê, Ocón analisa uma obra de Abū Ùthman 'Amr ibn Bahr al-Jāhiziz (c. 781-868), intelectual árabe dos primeiros séculos do domínio muçulmano do Mediterrâneo. Tendo vido na época das traduções de obras gregas e latinas, al-Jāhiz escreveu mais de duas centenas de trabalhos de natureza diversa, incluindo filosofia, teologia, retórica e zoologia. O objetivo

${ }^{10}$ De acordo com informação disponível em: encurtador.com.br/mpJ35. Acesso em 19 mar. 2020.

Heródoto, Unifesp, Guarulhos, v. 4, n. 2, 2019.2 p. 07-17

DOI: $10.34024 /$ herodoto.2019.v4.10959 
principal do estudo de Jorge Ocón indica sua considerável relevância nos dias atuais, pois consiste em demonstrar que, em uma obra até hoje vista apenas como satírica, há a defesa do protagonismo negro na história daquela sociedade. Surpreenderá a leitores que, como eu, são ignorantes da história árabe, saber que os negros foram considerados "burros, feios, horríveis", sem virtudes e façanhas que os distinguissem. E que al-Jāhiz, negro e de origem humilde, teria se oposto a esta visão também reelaborando uma particular Antiguidade, aquela próxima da expansão do Islã, incluindo reinos africanos, árabes e o Império Sassânida dos séculos VI e VII.

De Atenas a Pataliputra: historiografía sobre contactos entre griegos e indios durante el Periodo Helenístico também pode ser classificado como singular pelo seu objeto de estudo: a historiografia a respeito das relações entre gregos e indianos a partir da invasão macedônia. Sem invocar a ideia de recepção, Ezequiel Martin Parra, professor da Universidad Nacional de Córdoba, avalia comparativamente as visões do britânico (sir) William Woodthorpe Tarn (1869-1957) e dos indianos Awadh Kishore Narain (1925-2003), historiador, e Jawaharlal Nehru (1889-1964), o conhecido político dos primeiros tempos da Índia independente. Temos, pois, uma avaliação comparativa de um colonialista e de dois indianos, póscolonialistas, a respeito do contato entre gregos e indianos na Antiguidade. Não surpreenderá saber que estes estudos de um antigo passado tratavam também dos tempos da conquista e da dominação britânica do subcontinente indiano. A tese defendida por Ezequiel Parra, contudo, surpreenderá os leitores.

Os artigos restantes guardam outros gêneros de surpresa.

Logo na abertura de Um poeta latino e uma lira paulista, uma tradução esquecida de um epigrama de Marcial, Fábio Paifer Cairoli (professor de Língua e Literatura Latina da Universidade Federal Fluminense), observa como a recepção da Antiguidade é dependente da intenção do pesquisador identificar tal gênero de apropriação. Porque é provável terem muitos estudiosos investigado o jornal paulista $O$ Pirralho, sem atentar para a inusitada, aos nossos olhos, tradução presente na edição 11, de 21 de outubro de 1911. Não há razão para censura, pois se houve realmente outros investigadores-leitores, seus objetivos certamente eram outros e, por causa disso, suas questões devem ter propiciado outro gênero de apropriação daquele documento.

Heródoto, Unifesp, Guarulhos, v. 4, n. 2, 2019.2 p. 07-17

DOI: $10.34024 /$ herodoto.2019.v4.10959 
Os estudiosos da área de história bem conhecem uma das máximas da Escola dos Annales, de que o passado depende das questões daqueles que por ele se interessam (FEBVRE, 1971, p. 70). A recepção pretende algo até um pouco mais ousado: a constituição recíproca do presente e do passado. Martindale (2007, p. 298) sustenta esta ideia especialmente com base em pequeno texto de T.S. Elliot (Tradição e talento individual, de 1919); o mesmo é expresso pelo conceito de allelopoeise, formulado pelos componentes do projeto Imperial Interpretations: The Imperium Romanum as a Category of Political Reflection. Allelopoeise é uma conjunção dos termos gregos antigos allelon (recíproca) e poiesis (criação) (HAUSTEINER; HUHNHOLZ;WALTER, 2010, p.15) ${ }^{11}$. A ideia me parece presente ao longo da seção em que March Bloch critica o "privilégio de auto-inteligibilidade" do presente em sua Apologia da História. Considerando o momento de redação daquela obra12, destaco esta passagem:

Pois o frêmito da vida humana, que exige um duríssimo esforço de imaginação para ser restituído aos velhos textos, é [aqui] ${ }^{13}$ diretamente perceptível a nossos sentidos. Li muitas vezes, narrei frequentemente, relatos de guerra e de batalhas. Conhecia eu verdadeiramente, no sentido pleno do verbo conhecer, conhecia por dentro, antes de ter eu mesmo experimentado a atroz náusea, o que são, para um exército, o cerco, para um povo, a derrota? Na verdade, conscientemente ou não, é sempre a nossas experiências cotidianas que, para nuança-las onde se deve, atribuímos matizes novos, em última análise os elementos, que nos servem para reconstituir o passado: os próprios nomes que usamos a fim de caracterizar os estados de alma desaparecidos, as formas sociais evanescidas, que sentido teriam para nós se não houvéssemos antes visto homens viverem? Vale mais [cem vezes] substituir essa impregnação instintiva por uma observação voluntária e controlada. Um grande matemático não será menos grande (sic), suponho, por haver atravessado de olhos fechados o mundo onde se vive. Mas o erudito que não tem o gosto de olhar a seu redor os homens, nem as coisas, nem os acontecimentos, [ele] merecerá talvez, com dizia Pirene, o título de um útil antiquário. E agirá sensatamente renunciando ao de historiador. (2001, p.66)

Portanto, o projeto não é novo, mas parece ainda não realizado considerando a permanência do vocabulário da concepção objetivista do

${ }^{11}$ Agradeço ao colega Fábio Faversani por ter me informado sobre esta noção alguns anos atrás.

12 Para os estranhos à historiografia, informo ter sido escrito entre a derrota da França e 1941. Marc Bloch foi fuzilado pelos alemães em 1944.

${ }^{13}$ São acréscimos a uma redação anterior, presentes na edição brasileira.

Heródoto, Unifesp, Guarulhos, v. 4, n. 2, 2019.2 p. 07-17

DOI: 10.34024/herodoto.2019.v4.10959 
conhecimento histórico e as coetâneas rejeições da subjetividade e do relativismo. ${ }^{14}$

Sugiro ao leitor pensar nestes termos - os da constituição conjunta de presente e passado - os artigos deste dossiê, inclusive o de Luís Carlos Passos Martins - Historia Magistra Vitae: Roma como tópico de História Universal na interpretação do Brasil Contemporâneo. Resultado de um projeto sobre a reapropriação brasileira de tópicos da política romana no discurso didático-pedagógico e na política contemporânea, o artigo do professor da PUCRS mostra a existência de uma versão moralista-conservadora do presente brasileiro e do passado romano em postagens de internet dos períodos turbulentos em que vivemos. O principal componente de seu corpus documental sãs "falas não autorizadas", isto é, postagens não acadêmicas, o que aumenta a relevância de seu trabalho. Nelas, decadência continua a ser a noção-chave da constituição recíproca de presente e passado: Luís Carlos Martins oferece uma pequena recapitulação da apropriação do tema na "história intelectual do Ocidente". O texto define seus conceitos, apresenta seu corpus e os procedimentos metodológicos de sua análise, o que será de muita utilidade para os interessados em investigações análogas. As dificuldades não são poucas, a começar pela definição dos parâmetros de pesquisa no Google.

Fábio Vergara Cerqueira e Isabel Halfen da Costa Torino classificam como um "fenômeno da Recepção da Antiguidade" a instalação de uma estátua de Mercúrio no alto da torre do Mercado Central de Pelotas, na segunda década do século XX. As estátuas do "Mercúrio Voador" em Pelotas e no Brasil, o colega da UFPEL e a doutoranda do Programa de Pós-graduação em Memória Social e Patrimônio Cultural da mesma universidade trata da atribulada história da estátua, mas também de outras representações de Mercúrio em Pelotas e outras cidades brasileiras. O artigo apresenta reflexões sobre aquela apropriação, defendendo ter isso um indício da identidade pretendida entre a elite da então próspera cidade do sul

${ }^{14}$ Em razão de seus pressupostos teóricos, a Estética da Recepção, mesmo que imaginada para a Teoria Literária, apresenta importância evidente para Teoria Histórica, como atesta este comentário de Luiz Costa Lima: “que a História, não por alguma falha conjuntural mas por consequência de seu próprio método objetivista, se mostra incapaz de não se ver atada às malhas que a prendem à sua ambiência temporal. A falência do objetivismo é do historiador à medida que é de toda criatura humana: a impossibilidade de tomar consciência e de então se desligar dos efeitos [destaque original] provocados pela maneira como sua circunstância histórica, com seus valores, usos, costumes e tradições, está constituída."(2002, p. 23)

Heródoto, Unifesp, Guarulhos, v. 4, n. 2, 2019.2 p. 07-17

DOI: 10.34024/herodoto.2019.v4.10959 
brasileiro e certa concepção da Antiguidade. É ainda mais relevante porquanto insere o que poderia parecer um acontecimento secundário na história da pretensão civilizatória que grassou em nosso país no início do século XX. Não se tratava de "imitação" mas de ato ligado à identidade urbana de certos setores da sociedade brasileira. Todo o texto é acompanhado por imagens e reproduções de outros Mercúrios instalados no mesmo período por outras elites urbanas de nosso país.

O texto de Fernando Mattiolli Vieira, professor da Universidade Federal de Pernambuco, complementa este número de Heródoto com relevante avaliação do conflito entre Arqueologia e História no tocante às relações entre os manuscritos e o(s) assentamento(s) de Qumran. História e Arqueologia e os debates sobre os Manuscritos de Qumran não é um trabalho do campo da Recepção, mas complementa de forma admirável esta publicação pela qualidade e pela relevância de um texto que mostra as imprecisões das análises históricas, muitas delas compreensíveis pela impossibilidade de rompermos com nossa participação significativa nos tempos em que vivemos. Este gênero de trabalho também é importante para, como escreveu Norma Cortês, fazermos "uma atenta observação de nós mesmos". Esta teorização somente pode ser efetiva se abandonarmos a ilusão de sermos abençoados com um privilégio epistêmico capaz de nos eximir daquilo que nos faz humanos e historiadores.

\section{Referências bibliográficas}

ARMSTRONG, Karen. Uma História de Deus. Quatro milênios de busca do Judaísmo, Cristianismo e Islamismo. São Paulo: Companhia das Letras, 1994 (1993).

BAKOGIANNI, Anastacia. O que há de tão 'clássico' na recepção dos clássicos? Teorias, metodologias e perspectivas futuras. Codex - Revista de Estudos Clássicos, Rio de Janeiro, v. 4, n. 1, p. 96-113, 2016.

CORTÊS, Norma. Desafios hermenêuticos: as noções de tempo e tradição em Hans-Georg Gadamer. In: BUSTAMANTE, Regina e LESSA, Fábio (orgs.) Dialogando com Clio. Rio de Janeiro: Mauad, 2009.

FEBVRE, Lucien. De cara ao viento. Manifiesto de los nuevos Annales. In: Combates por la Historia. $2^{\mathrm{a}}$ ed. Barcelona: Ariel, 1971. p. 59-71.

GINZBURG, Carlo. Introdução. In: Relações de força. História, retórica e prova. São Paulo: Companhia das Letras, 2002 (2000). p. 13-45.

Heródoto, Unifesp, Guarulhos, v. 4, n. 2, 2019.2 p. 07-17

DOI: $10.34024 /$ herodoto.2019.v4.10959 
HARDWICK, Lorna. Reception Studies. Greece \& Rome: New Surveys in the Classics $n^{\circ} 33$. Oxford, Reino Unido: Oxford University Press for the Classical Association, 2003.

HAUSTEINER, Eva Marlene; HUHNHOLZ, Sebastian; WALTER, Marco. Imperial interpretations: The imperium romanum as a category of political reflexion. Mediterraneo Antico. Roma, Fabrizio Serra, v. 12, n. 1-2, p. 11-15, 2010.

LIMA, Luiz Costa. Prefácio à $2^{\mathrm{a}}$ ed.; Prefácio à $1^{\mathrm{a}}$ ed.: O leitor demanda (d)a Literatura. In: A literatura e o leitor. Textos de estética da recepção. $2^{\mathrm{a}} \mathrm{ed}$. revista e ampliada. Rio de Janeiro: Paz e Terra, 2002 (1979). p. 9-66.

MARTINDALE, Charles. Redeeming the text. Latin poetry and the hermeneutics of reception. Cambridge: Cambridge UP, 1993.

Reception. In: KALLENDORF, Craig W. (ed.). A Companion to the Classical Tradition. Oxford: 2007. p. 297-311.

TATUM, James. A Real Short Introduction to Classical Reception Theory. Arion: A Journal of Humanities and the Classics, Boston, Univ. of Boston, v. 22, n. 2, p. 75-96, 2014. 